\title{
Front Matter: Volume 8910
}

, "Front Matter: Volume 8910," Proc. SPIE 8910, International Symposium on Photoelectronic Detection and Imaging 2013: Imaging Spectrometer Technologies and Applications, 891001 (30 August 2013); doi: $10.1117 / 12.2042808$

SPIE Event: ISPDI 2013 - Fifth International Symposium on Photoelectronic SPIE. Detection and Imaging, 2013, Beijing, China 


\title{
International Symposium on Photoelectronic Detection and Imaging 2013
}

\section{Imaging Spectrometer Technologies and Applications}

\author{
Lifu Zhang \\ Jianfeng Yang \\ Editors
}

\section{5-27 June 2013 \\ Beijing, China}

\section{Organized by}

Photoelectronic Technology Committee, Chinese Society of Astronautics • Tianjin Jinhang Institute of Technical Physics (China) - Science and Technology on Low Light Level Night Vision Laboratory (China) - Science and Technology on Optical Radiation Laboratory (China) • Science and Technology on Electromagnetic Scattering Laboratory (China)

Sponsored by

SPIE • The Optical Society • European Optical Society • Chinese Society of Astronautics

Published by

SPIE 
The papers included in this volume were part of the technical conference cited on the cover and title page. Papers were selected and subject to review by the editors and conference program committee. Some conference presentations may not be available for publication. The papers published in these proceedings reflect the work and thoughts of the authors and are published herein as submitted. The publisher is not responsible for the validity of the information or for any outcomes resulting from reliance thereon.

Please use the following format to cite material from this book:

Author(s), "Title of Paper," in International Symposium on Photoelectronic Detection and Imaging 2013: Imaging Spectrometer Technologies and Applications, edited by Lifu Zhang, Jianfeng Yang, Proceedings of SPIE Vol. 8910 (SPIE, Bellingham, WA, 2013) Article CID Number.

ISSN: 0277-786X

ISBN: 9780819497796

Published by

SPIE

P.O. Box 10, Bellingham, Washington 98227-0010 USA

Telephone +1 3606763290 (Pacific Time) · Fax +1 3606471445

SPIE.org

Copyright (C) 2013, Society of Photo-Optical Instrumentation Engineers.

Copying of material in this book for internal or personal use, or for the internal or personal use of specific clients, beyond the fair use provisions granted by the U.S. Copyright Law is authorized by SPIE subject to payment of copying fees. The Transactional Reporting Service base fee for this volume is $\$ 18.00$ per article (or portion thereof), which should be paid directly to the Copyright Clearance Center (CCC), 222 Rosewood Drive, Danvers, MA 01923. Payment may also be made electronically through CCC Online at copyright.com. Other copying for republication, resale, advertising or promotion, or any form of systematic or multiple reproduction of any material in this book is prohibited except with permission in writing from the publisher. The CCC fee code is 0277-786X/13/\$18.00.

Printed in the United States of America.

Publication of record for individual papers is online in the SPIE Digital Library.

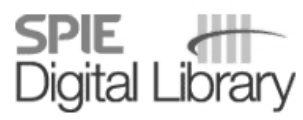

SPIEDigitallibrary.org

Paper Numbering: Proceedings of SPIE follow an e-First publication model, with papers published first online and then in print and on CD-ROM. Papers are published as they are submitted and meet publication criteria. A unique, consistent, permanent citation identifier (CID) number is assigned to each article at the time of the first publication. Utilization of CIDs allows articles to be fully citable as soon as they are published online, and connects the same identifier to all online, print, and electronic versions of the publication. SPIE uses a six-digit CID article numbering system in which:

- The first four digits correspond to the SPIE volume number.

- The last two digits indicate publication order within the volume using a Base 36 numbering

system employing both numerals and letters. These two-number sets start with 00, 01, 02, 03, 04, $05,06,07,08,09,0 A, 0 B \ldots 0 Z$, followed by 10-1Z, 20-2Z, etc.

The CID Number appears on each page of the manuscript. The complete citation is used on the first page, and an abbreviated version on subsequent pages. Numbers in the index correspond to the last two digits of the six-digit CID Number. 


\title{
Contents
}

\author{
xi Conference Committee \\ xiii Introduction
}

891002 Traceability of spectroradiometric measurements of multiport UV solar simulators [8910-2] C. Dai, Z. Wu, X. Qi, J. Ye, National Institute of Metrology (China); B. Chen, National Institute of Metrology (China) and Beijing Institute of Technology (China)

891003 The extraction of characteristic wavebands for radish leaves and rice leaves based on LCTF imaging method [8910-3]

P. Cao, J. Feng, H. Li, Yunnan Normal Univ. (China)

891004 Theoretical and experimental study on a compact static spectropolarimeter [8910-4] X. Lin, F. Zhou, H. Li, H. Zhao, S. Yang, Beijing Institute of Space Mechanics and Electricity (China)

891005 Curvelet based hyperspectral image fusion [8910-11]

S. Wang, H. Feng, Z. XU, Q. Li, Y. Chen, Zhejiang Univ. (China)

891006 Detection of camouflaged targets using hyperspectral imaging technology [8910-14] J. Yang, W. Hua, Z. Ma, Y. Zhang, Mechanical Engineering College (China)

891007 Scattered light: improving photoacoustic spectral measurement with a drug tablet [8910-15]

R. YU, Y. Jiang, BeiHang Univ. (China); L. Yu, Lanzhou Univ. (China); D. Wen, H. Hua, X. Wu, BeiHang Univ. (China)

891008 Research on temperature calibration of extended area blackbody based on two-point multi-section linear correction algorithm [8910-16]

S. Han, W. Hu, W. Luo, R. Wang, China Electronics Technology Group Corp. (China)

891009 Design of an infrared three-mirror optical system with large relative aperture [8910-17] Y. Bai, Institute of Optics and Electronics (China), Univ. Of Electronic Science and Technology of China (China) and Univ. of Chinese Academy of Sciences (China); S. Liao, $\mathrm{H}$. Li, T. Xing, Institute of Optics and Electronics (China); Y. Jiang, Univ. of Electronic Science and Technology of China (China)

8910 OA The research of apodization method of Fourier transform spectrometer [8910-19] P. Zhang, Z. Zhang, S. Han, China Electronics Technology Group Corp. (China)

$8910 \mathrm{OB}$ Design of a concise Féry-prism hyperspectral imaging system based on multi-configuration [8910-20]

W. Dong, Univ. of Chinese Academy of Sciences (China) and Academy of OptoElectronics (China); Y. Nie, J. Zhou, Academy of Opto-Electronics (China) 
8910 0C Calculate IR optical constants of Si substrate under high temperature condition [8910-22] Y. Jiang, Tongji Univ. (China) and Tianjin Jinhang Institute of Technical Physics (China);

L. Wang, H. Liu, D. Liu, C. Jiang, Tianjin Jinhang Institute of Technical Physics (China);

D. Chen, Harbin Institute of Technology (China); Y. Yang, Tongji Univ. (China); Y. Ji, Tianjin Jinhang Institute of Technical Physics (China) and Harbin Institute of Technology (China)

8910 OD Realization of the new national primary scale of spectral radiance and spectral irradiance [8910-24]

C. Dai, Z. Wu, J. Yu, National Institute of Metrology (China)

8910 OE Alignment off-axis optical system using Nodal Aberration Theory [8910-27]

B. Jiang, Xi'an Institute of Optics and Precision Mechanics (China) and Univ. Of Chinese Academy of Sciences (China); S. Zhou, Xi'an Institute of Optics and Precision Mechanics (China); K. Jiang, H. Fu, C. Mei, Xi'an Institute of Optics and Precision Mechanics (China) and Univ. of Chinese Academy of Sciences (China)

8910 OF Rendered virtual view image objective quality assessment [8910-28]

G. LU, X. Li, Y. Zhang, K. Peng, Huazhong Univ. of Science and Technology (China)

89100 Optical system design of visible camera for space debris [8910-29]

H. Wang, Northwestern Polytechnical Univ. (China) and Xi'an Institute of Optics and Precision Mechanics (China); J. Luo, Northwestern Polytechnical Univ. (China)

$8910 \mathrm{OH}$ Design of hybrid refractive-diffractive visible lens with small F-number [8910-30] $\mathrm{H}$. Wang, Northwestern Polytechnical Univ. (China) and Xi'an Institute of Optics and Precision Mechanics (China); J. Luo, Northwestern Polytechnical Univ. (China)

8910 ol The research of spectrophotometric color matching based on multi-peaks Gaussian fit [8910-31]

X. Li, X. LV, The PLA Univ. of Science and Technology (China); J. Wang, Institution of Acoustics (China); G. Yang, The PLA Univ. of Science and Technology (China); X. Jiang, The First Engineer Scientific Research Institute of the General Armaments Dept. (China)

$89100 \mathrm{~J}$ Application research on enhancing near-infrared micro-imaging quality by $2^{\text {nd }}$ derivative [8910-32]

D. Wang, Z. Ma, L. Zhao, B. Wang, P. Han, L. Pan, J. Wang, Beijing Research Ctr. for Agri-food Testing and Farmland Monitoring (China)

8910 OK An algorithm used for quality criterion automatic measurement of band-pass filters and its device implementation [8910-33]

Q. Liu, Y. Liu, F. Yu, Zhejiang Univ. (China)

$8910 \mathrm{OL} \quad$ Research on atmospheric pressure plasma processing sewage [8910-34]

G. Song, Y. Na, X. Dong, X. Sun, Changchun Univ. of Science and Technology (China)

$89100 \mathrm{M}$ Sparse representation based multi-threshold segmentation for hyperspectral target detection [8910-35]

W. Feng, Nanjing Univ. of Science and Technology (China) and Science and Technology on Low-Light-Level Night Vision Lab. (China); Q. Chen, Nanjing Univ. of Science and Technology (China); Z. Miao, Science and Technology on Low-Light-Level Night Vision Lab. (China); W. He, G. GU, J. Zhuang, Nanjing Univ. of Science and Technology (China) 
8910 ON Polarization image fast fusion method based on online dictionary learning [8910-36] G. Xu, M. Xue, Hefei Univ. of Technology (China) and New Star Research Institute of Applied Technology (China); G. Yuan, P. Zhou, New Star Research Institute of Applied Technology (China)

891000 Multi-satellites normalization of the FengYun-2s visible detectors by the MVP method [8910-38]

Y. Li, Z. Rong, L. Zhang, L. Sun, N. Xu, China Meteorological Administration (China)

$89100 Q$ Optical design of a static LWIR Fourier-transform imaging spectrometer with high throughput [8910-40]

$\mathrm{H}$. Wang, Y. Fu, W. Zheng, Beijing Institute of Technology (China) and Kunming Institute of Physics (China); N. Liao, W. Jin, Beijing Institute of Technology (China)

8910 OR Analysis of the modulation efficiency of imaging Fourier transform spectrometers [8910-41] Y. Fu, X. Li, W. Zheng, Beijing Institute of Technology (China) and Kunming Institute of Physics (China); N. Liao, Beijing Institute of Technology (China); J. Su, Kunming Institute of Physics (China)

8910 OS Dimension reduction for hyperspectral image based on the second generation bandelet transform [8910-42]

X. Du, H. Chen, The Academy of Equipment Command \& Technology (China); Z. Liu, Harbin Institute of Technology (China); M. Liu, X. Cheng, The Academy of Equipment Command \& Technology (China)

8910 OT Image reconstruction from partial pseudo polar Fourier sampling based on alternating direction total variation minimization [8910-43]

Q. Liu, F. Shu, W. Zhang, A. Cai, L. Li, B. Yan, National Digital Switching System Engineering and Technology Research Ctr. (China)

8910 OU Effect analysis of spectral calibration error of space-borne imaging spectrometer [8910-44] M. Li, J. Ma, Beijing Institute of Space Mechanics and Electricity (China)

$89100 \mathrm{~V}$ Spectral discrimination of an invasive species (Spartina alterniflora) in Min River wetland using field spectrometry [8910-46]

J. Ai, W. Chen, L. Chen, Fujian Normal Univ. (China)

$8910 \mathrm{OW}$ Effect of the fringe visibility on spectrum SNR of Fourier transform imaging spectrometer [8910-47]

S. Wang, Xi'an Institute of Optics and Precision Mechanics (China) and Univ. of Chinese Academy of Sciences (China); X. Bin, Academy of Opto-Electronics (China); J. Jing, H. Pi, $X i$ 'an Institute of Optics and Precision Mechanics (China) and Univ. of Chinese Academy of Sciences (China)

$89100 \mathrm{X}$ Study on near-far ultraviolet imaging spectrometer with high resolution [8910-48] $\mathrm{H}$. Cong, Harbin Institute of Technology (China) and Changchun Univ. of Science and Technology (China); C. Wang, Harbin Institute of Technology (China); Y. Wang, Changchun Univ. of Science and Technology (China) 
8910 OY Binary 3D image interpolation algorithm based global information and adaptive curves fitting [8910-49]

T. Zhang, Air Defense Forces Academy (China); J. Zhang, Zheng Zhou Automation Institute

(China); X. Guan, Q. Li, M. He, Air Defense Forces Academy (China)

$89100 Z$ Computer-aided alignment of off-axis three-mirror imaging spectrometer system [8910-50]

D. Gong, H. Wang, T. Tian, Changchun Institute of Optics, Fine Mechanics and Physics (China)

891010 Design of high-speed multi-channel TDICCD image acquisition and processing system based on FPGA [8910-51]

G. Zhai, Y. Cheng, L. Zhang, Beijing Institute of Space Mechanics and Electricity (China)

891011 Research on methods of spectral calibration and radiometric calibration of the windowing Fourier transform imaging spectrometer [8910-52]

L. Zhang, J. B. Gao, Y. J. Zhao, Y. L. Luo, X. G. Xiao, F. Zhang, Xi'an Institute of Applied Optics (China)

891013 Hyperspectral subspace estimation preserving anomalies via a test of multivariate sample skewness [8910-57]

S. Zheng, S. Zhou, L. Wang, Z. Li, National Univ. of Defense Technology (China)

891014 Design of camera and spectrometer dual-use system [8910-60]

Y. Qi, Xi'an Institute of Optics and Precision Mechanics (China) and Univ. of Chinese Academy of Sciences (China); B. Xue, Xi'an Institute of Optics and Precision Mechanics (China); Y. Zhao, J. Tao, Xi'an Institute of Optics and Precision Mechanics (China) and Univ. of Chinese Academy of Sciences (China)

891015 Research on marine and freshwater fish identification model based on hyper-spectral imaging technology [8910-61]

Y. Fu, P. Guo, L. Xiang, M. Bao, X. Chen, Beijing Technology and Business Univ. (China)

891016 Study on the radiation property of high temperature gas relation with flight altitude and velocity (Invited Paper) [8910-62]

W. Meng, Beijing Institute of Technology (China) and Luoyang Optoelectro Technology Development Ctr. (China); H. Xu, J. Xiang, J. Song, Luoyang Optoelectro Technology Development Ctr. (China)

891017 Remote sensing images fusion based on block compressed sensing [8910-63] S. Yang, Xi'an Univ. of Arts and Science (China); G. Wan, Northwestern Polytechnical Univ. (China); B. Zhang, Xi' an Univ. of Arts and Science (China); X. Chong, Emerson Network Power Ltd. (China)

891018 A hp adaptive finite element algorithm for fluorescence molecular tomography based on SPN model [8910-64]

H. Guo, Y. Hou, X. He, Northwest Univ. (China); J. Yu, Shaanxi Normal Univ. (China);

J. Cheng, X. Pu, Northwest Univ. (China)

891019 Possibilities of visible-near infrared spectroscopy for rapid diagnosis of diseases [8910-66] J. Zhao, Tianjin Univ. of Traditional Chinese Medicine (China) and Tianjin Univ. (China); M. Liu, Tianjin Univ. (China); X. Lu, Tianjin Univ. of Traditional Chinese Medicine (China); G. Li, Tianjin Univ. (China) 
$89101 \mathrm{~A} \quad$ Compact and static Fourier transform imaging spectropolarimeters using birefringent elements [8910-67]

T. Mu, C. Zhang, W. Ren, C. Jia, L. Zhang, Q. Li, Xi'an Jiaotong Univ. (China)

8910 1B Data reconstructing for windowing broom Fourier transform imaging spectrometers based on multi-core techniques [8910-68]

Z. Dong, N. Liao, L. Qu, H. Lv, Beijing Institute of Technology (China)

$89101 \mathrm{C}$ Calibration and correction of the CCD spectral response nonuniformity for Fourier transform imaging spectrometer [8910-69]

D. Shi, Xi' an Institute of Optics and Precision Mechanics (China) and Univ. of Chinese Academy of Sciences (China); X. Liu, Xi' an Institute of Optics and Precision Mechanics (China); S. Wang, Xi'an Institute of Optics and Precision Mechanics (China) and Univ. of Chinese Academy of Sciences (China); J. Jing, Academy of Opto-Electronics (China); D. Wen, Q. Bai, Xi'an Institute of Optics and Precision Mechanics (China)

8910 1D Extracting of removal function in CCOS based on edge detection algorithm [8910-70] J. Liu, S. Wang, L. Zhang, H. Chen, Changchun Institute of Optics, Fine Mechanics and Physics (China)

$89101 \mathrm{E} \quad$ Analysis and design of imaging Fabry-Perot interferometers for measurement of Rayleigh-Brillouin scattering spectra in gas flows [8910-72] T. Li, G. Li, L. Wu, L. Yuan, B. Yu, X. Wang, H. Yang, L. Wu, L. Wang, D. Yu, W. Yin, Xi'an Institute of Applied Optics (China)

$89101 \mathrm{~F}$ The design and performance of infrared beamline at SSRF [8910-74] Y. Tong, T. Ji, Z. Zhang, H. Zhu, W. Peng, M. Chen, T. Xiao, Shanghai Institute of Applied Physics (China)

$89101 \mathrm{G}$ The Hughes phenomenon in hyperspectral classification based on the ground spectrum of grasslands in the region around Qinghai Lake [8910-75]

W. Ma, C. Gong, Y. Hu, P. Meng, F. Xu, Shanghai Institute of Technical Physics (China)

$89101 \mathrm{H} \quad$ The optical design of multispectral camera [8910-76]

T. Tian, Changchun Institute of Optics, Fine Mechanics and Physics (China)

891011 A new SNR model for space-borne hyperspectral imagers including atmospheric scattering influence [8910-77]

J. Lang, Shanghai Institute of Technical Physics (China) and Univ. of Chinese Academy of Sciences (China); Y. Wang, J. Wang, Shanghai Institute of Technical Physics (China)a

$89101 \mathrm{~J} \mathrm{Research} \mathrm{of} \mathrm{high} \mathrm{power} \mathrm{and} \mathrm{stable} \mathrm{laser} \mathrm{in} \mathrm{portable} \mathrm{Raman} \mathrm{spectrometer} \mathrm{based} \mathrm{on}$ SHINERS technology [8910-78]

Y. Cui, Y. Yin, Y. Wu, X. Ni, X. Zhang, H. Yan, Zhejiang Univ. (China)

$89101 \mathrm{~K}$ The research of digital circuit system for high accuracy CCD of portable Raman spectrometer [8910-80]

Y. Yin, Y. Cui, X. Zhang, H. Yan, Zhejiang Univ. (China) 
$89101 \mathrm{~L}$ The influence of co-phasing error on image quality in synthesized aperture telescope [8910-81]

L. Zhang, W. Zhao, Beijing Institute of Technology (China); Y. Li, Beijing Institute of Remote Sensing Equipment (China)

$89101 \mathrm{M}$ Multi-layer filtering approach for hyperspectral target detection [8910-83]

Z. Zou, Z. Shi, Beihang Univ. (China)

$89101 \mathrm{~N}$ Automatic identification and tracking the Arctic sea ice based on sequential images of FY-3A satellite [8910-84]

Y. Zhou, Shanghai Institute of Technical Physics (China) and Univ. of Chinese Academy of Sciences (China); C. Gong, Y. Hu, P. Meng, Shanghai Institute of Technical Physics (China); W. Ma, Shanghai Institute of Technical Physics (China) and Univ. of Chinese Academy of Sciences (China)

891010 Tolerance analysis of multispectral camera optical system [8910-89]

$\mathrm{H}$. Wang, Changchun Institute of Optics, Fine Mechanics and Physics (China)

8910 IP Analysis for signal-to-noise ratio of hyper-spectral imaging FTIR interferometer [8910-90] $X$. Li, W. Zheng, Kunming Institute of Physics (China) and Beijing Institute of Technology (China); Z. Lei, Kunming Institute of Physics (China); H. Wang, Y. Fu, Kunming Institute of Physics (China) and Beijing Institute of Technology (China)

$89101 Q$ Recognition of camouflage targets with hyper-spectral polarization imaging system [8910-91]

Q. Wang, J. Wang, D. Zhao, Electronic Engineering Institute (China); L. Ma, Academy of Army Officers (China); Z. Chen, Z. Li, Electronic Engineering Institute (China)

$89101 R \quad$ GPU-based parallel algorithm for blind image restoration using midfrequency-based methods [8910-92]

L. Xie, Y. Luo, Q. Bao, Institute of Optics and Electronics (China)

8910 is Effect analysis of oil paint on the space optical contamination [8910-93]

C. Lu, H. Lv, C. Han, H.-B. Wei, Harbin Engineering Univ. (China)

$89101 \mathrm{~T}$ Terahertz time-domain spectroscopy of D-glucose in the solution states [8910-94]

Z. Jiang, Y. Wang, Capital Normal Univ. (China); X. Li, Beijing LED Lighting Engineering Co. Ltd. (China); C. Lu, W. Liu, Capital Normal Univ. (China); P. Sun, Beijing Normal Univ. (China); L. Miao, Capital Normal Univ. (China)

$89101 \mathrm{U}$ The generating mechanism of strips and destriping algorithm of $\mathrm{HJ}$-1A Hyperspectral Image [8910-95]

X. Gao, Xi'an Institute of Optics and Precision Mechanics (China); G. Xu, Xi'an Aerotechnical College (China); T. Yu, R. Wei, Xi'an Institute of Optics and Precision Mechanics (China)

$89101 \mathrm{~V}$ Effect of assembly error of polarization array on a Polarizing Atmospheric Michelson Interferometer [8910-97]

L. Zhang, C. Zhang, W. Ren, J. Wang, Xi'an Jiaotong Univ. (China) 
$89101 \mathrm{~W}$ Multi-shot encoded compressive imaging method for super-resolution (Invited Paper) [8910-98]

J. Du, X. Shao, C. Zhong, Xidian Univ. (China)

$89101 \mathrm{X}$ Optimum design of a holographic parallel flat-field grating [8910-99]

Q. Wang, Z. Liu, H. Chen, S. Fu, Univ. of Science and Technology of China (China)

$89101 Y$ Fourier transform imaging spectrometry using Sagnac interferometer [8910-100]

J. Li, W. Zhou, X. Meng, D. Liu, R. Zhu, Nanjing Univ. of Science and Technology (China)

891012 Optical system design of polarization imaging spectrometer for ground-based astronomical observation [8910-104]

L. Chang, Xi'an Univ. of Post and Telecommunications (China); D. Yao, B. Zhao, Y. Qiu, Xi'an Institute of Optics and Precision Mechanics (China)

891020 Assessment and mapping of soil nitrogen using Visible-Near-Infrared (Vis-NIR) spectra [8910-107]

X. Liu, Y. Guo, Q. Wang, J. Zhang, Z. Shi, Zhejiang Univ. (China)

$891021 \quad$ Integrated in instrument and measurement system by general global concept [8910-108] C. Guo, Q. Ding, Luoyang Institute of Electro-Optical Equipment (China); L. Zhou, Beijing Institute of Technology (China); H. Liu, Luoyang Institute of Electro-Optical Equipment (China)

891022 Insights into esophagus tissue architecture using two-photon confocal microscopy [8910-109]

N. Liu, Y. Wang, S. Feng, R. Chen, Fujian Normal Univ. (China)

891023 Research of a new model for abundance estimation [8910-110]

H. Xie, M. Song, B. Lin, J. An, Dalian Maritime Univ. (China)

891025 Estimating oil thickness by simplified Hapke model [8910-112]

M. Song, R. Lin, J. An, Dalian Maritime Univ. (China); H. Bao, Dalian Nationalities Univ. (China)

891026 Active contour segmentation for hyperspectral oil spill remote sensing (Invited Paper) [8910-113]

M. Song, M. Chang, J. An, J. Huang, B. Lin, Dalian Maritime Univ. (China)

891027 3D surface scan of biological samples with a Push-broom Imaging Spectrometer (Invited Paper) [8910-114]

H. Yao, R. Kincaid, Z. Hruska, Mississippi State Univ. (United States); R. L. Brown,

D. Bhatnagar, T. E. Cleveland, Agricultural Research Service (United States)

891029 Calculation angle and amplitude spectrum of interferogram with FPGA [8910-500]

J. Liu, L. Ding, Shanghai Institute of Technical Physics (China)

8910 2A Improving the spectral resolution of soft $x$-ray flat-field spectrometer with multi-area gratings [8910-116]

H. Chen, Z. Liu, Q. Wang, S. Fu, Univ. of Science and Technology of China (China)

Author Index 


\title{
Conference Committee
}

\author{
Conference Chairs
}

Konstantin Vodopyanov, Stanford University (United States) and CREOL, The College of Optics and Photonics, University of Central Florida (United States)

Guofan Jin, Tsinghua University (China)

Songlin Zhuang, University of Shanghai for Science and Technology (China)

Local Organizing Committee

Jiaqi Wang, Changchun Institute of Optics, Fine Mechanics and Physics (China)

Zuyan Xu, Technical Institute of Physics and Chemistry (China)

Zunqi Lin, Shanghai Institute of Optics and Fine Mechanics (China)

Dianyuan Fan, Shanghai Institute of Optics and Fine Mechanics (China)

Jingshan Jiang, Center for Space Science and Applied Research (China)

Liwei Zhou, Beijing Institute of Technology (China)

Shouhuan Zhou, North China Research Institute of Electro-optics (China)

Desheng Jiang, Wuhan University of Technology (China)

Jianquan Yao, Tianjin University (China)

Qingxi Tong, Institute of Remote Sensing and Digital Earth (China)

Junhao Chu, Shanghai Institute of Technical Physics (China)

Yongqi Xue, Shanghai Institute of Technical Physics (China)

Program Committee

Junhao Chu, Chair, Shanghai Institute of Technical Physics (China)

Jinxue Wang, Chair, Raytheon Company (United States)

Min Gu, Swinburne University of Technology (Australia)

Andreas Tünnermann, Friedrich-Schiller-Universität Jena (Germany)

Connie Chang, University of California, Berkeley (United States)

Shibin Jiang, AdValue Photonics Inc. (United States)

H. C. Liu, Shanghai Jiao Tong University (China)

Xiaocong Yuan, Nankai University (China)

Wei Shi, Tianjin University (China)

Min Qiu, Zhejiang University (China)

Nanjian Wu, Institute of Semiconductors (China)

\section{Session Chairs}

Imaging Spectrometer Technologies and Applications

Bormin Huang, University of Wisconsin-Madison (United States)

Mark Berman, CSIRO Mathematics, Informatics and Statistics (Australia)

Lifu Zhang, Institute of Remote Sensing and Digital Earth (China)

Jianfeng Yang, Xi'an Institute of Optics and Precision Mechanics (China) 


\section{Introduction}

We have had the great honor of organizing the Fifth International Symposium on Photoelectronic Detection and Imaging (ISPDI) in Beijing. It was truly a great pleasure for us to greet the more than 1,200 participants from many different countries attending ISPDI 2013! I firmly believe that the symposium will become an important international event in the field of photoelectronic detection and imaging technology.

ISPDI 2013 was sponsored by SPIE, The Optical Society, European Optical Society, and the Chinese Society of Astronautics, and was organized by the Photoelectronic Technology Committee, Chinese Society of Astronautics, Tianjin Jinhang Institute of Technical Physics, Science and Technology on Low Light Level Night Vision Laboratory, Science and Technology on Optical Radiation Lab. and Science and Technology on Electromagnetic Scattering Lab. There were 26 cooperating organizations that supported the meeting. Nearly 850 papers were accepted for presentation at ISPDI 2013, contributed by over 1,370 authors from more than 10 countries, including the United States, United Kingdom, Germany, France, Norway, Australia, Canada, Japan, Korea, Russia, China, and so on. We had seven plenary speeches and 135 famous scientists and experts from home and abroad to present the invited talks at 10 different conferences.

The purpose of ISPDI 2013 is to provide a forum for the participants to report and review the innovative ideas and up-to-date progress and developments, and discuss the novel approaches to applications in the field of photoelectronic detection and imaging. It is sincerely hoped that the research and developments in optical and photoelectronic fields will be promoted, and that international cooperation and the sharing of common interests will be enhanced.

On behalf of Prof. Konstantin Vodopyanov, and the other conference chairs, and the Organization Committee of ISPDI, I would like to heartily thank our sponsors and cooperating organizations for all they have done for the meeting. Thanks also to all the authors for their contributions to the proceedings, to all of the participants and friends for their interest and efforts in helping us make the symposium possible, to the Program Committee for their effective work and valuable advice, and especially the ISPDI 2013 Secretariat and the SPIE staff for their tireless effort and outstanding service in preparing the meeting and publishing the conference proceedings.

Guofan Jin 